\title{
CONSTITUENT ORDER IN IMPROVISED GESTURE REFLECTS SPEAKER PERSPECTIVE
}

\author{
Fiona Kirton ${ }^{* 1}$, Marieke Schouwstra ${ }^{1}$, Jenny Culbertson ${ }^{1}$, Kenny Smith $^{1}$, and Simon Kirby ${ }^{1}$ \\ *Corresponding Author: s1354886@sms.ed.ac.uk \\ ${ }^{1}$ Centre for Language Evolution, University of Edinburgh, UK
}

The majority of languages with a dominant word order use either SOV or SVO (Dryer, 2013). The improvised gesture paradigm, in which participants use only gesture to convey information, is increasingly being used to investigate this asymmetry. In one of the earliest studies of this kind, Goldin-Meadow et al. (2008) claimed that Agent-Patient-Action, (here represented as APV but typically equated with SOV), reflects the 'natural' order of elements in improvised gesture. Other authors argue that APV is the natural order only for some types of event and that constituent order in improvised gesture reflects certain properties of an event, such as its temporal structure (Christensen et al., 2016) or the semantic relation between entities and actions (Schouwstra \& Swart, 2014). Meir et al. (2017) suggest that gesture order is conditioned on saliency: human entities are more cognitively salient than inanimate entities and are therefore expressed first. Here we investigate the role of saliency in more detail. We present evidence that manipulating the visual saliency of the agent can influence the relative order of other constituents.

Twenty-eight participants were shown pictures of scenes in which a human agent performed an action on an inanimate patient, for example, a man kicking a large potted plant (Fig. 1(a)). They were instructed to describe each scene using only improvised gesture and no speech. Participants were randomly assigned to one of two conditions: the 'generic' condition in which agents represented generic humans such as a man or a woman, or the 'character' condition where more visually salient agents were presented, such as a pirate or a punk. Patients were inanimate objects of a similar size to the agents and were depicted in a state of falling as a result of the action.

We found that in the subset of trials where the agent, patient and action were expressed exactly once, the predominant order in the character condition was AVP; in the generic condition the majority order was APV (Fig. 1(b)). However, looking across all trials, we found that participants were significantly more likely to omit the agent in the generic condition (62\% of trials) compared with the character condition $(17 \%)(\mathrm{p}<0.001)$. This suggests that participants in the 
generic condition may have attended more to the patient than to the agent.

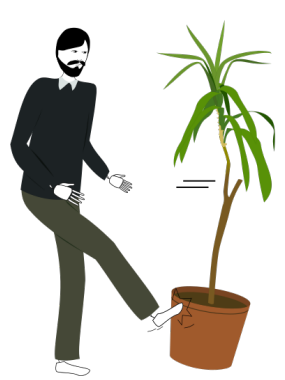

(a)

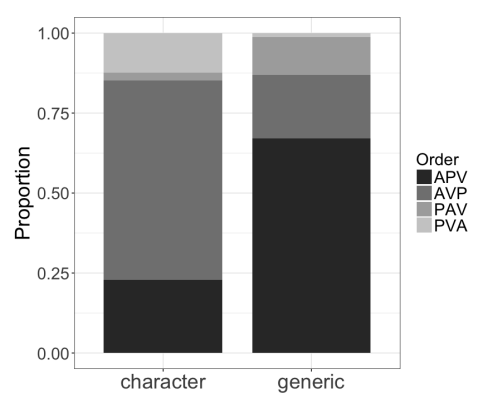

(b)

Figure 1. (a) An example event. (b) Proportions of three-element orders. Includes trials where the agent, patient and action were each expressed once.

Looking at the relative ordering of the patient, which was expressed in a majority of trials in both conditions, and the action, which was expressed on all trials, we found a significant effect of condition such that participants in the generic condition were more likely to express the patient before the action (78\%) compared with the character condition $(47 \%)(\mathrm{p}<0.05)$.

Based on these findings, we propose that structural choices in improvised gesture may reflect different ways of mentally construing events. In the generic condition, participants may tend to focus on the role of the patient and therefore construe the action as something that affects, or is experienced by, the patient. Hence, it is more natural to introduce the patient before the action is performed. In the character condition, participants may focus on the more visually salient agent, and so construe the event from the agent perspective: the action is represented as something performed by the agent, and directed towards to the patient. Hence, the agent and action more naturally precede the patient.

Previous studies (see references above) suggest that APV is the natural order only for certain types of event rather than the default structuring principle. Our results add an additional layer to that argument: naturalness as it relates to constituent order is conditioned on the properties of the event, but is also mediated by the way in which speakers construe an event. This, in turn, is influenced by the visual saliency of the participants in the event. The finding that visual attention affects structural choices is not new (e.g., Gleitman et al., 2007), however this is the first time to our knowledge that it has been demonstrated in improvised gesture. 


\section{References}

Christensen, P., Fusaroli, R., \& Tylén, K. (2016). Environmental constraints shaping constituent order in emerging communication systems: Structural iconicity, interactive alignment and conventionalization. Cognition, 146, 67-80.

Dryer, M. S. (2013). Order of subject, object and verb. In M. S. Dryer \& M. Haspelmath (Eds.), The world atlas of language structures online. Leipzig: Max Planck Institute for Evolutionary Anthropology.

Gleitman, L. R., January, D., Nappa, R., \& Trueswell, J. C. (2007). On the give and take between event apprehension and utterance formulation. Journal of Memory and Language, 57(4), 544-569.

Goldin-Meadow, S., So, W. C., Ozyürek, A., \& Mylander, C. (2008). The natural order of events: how speakers of different languages represent events nonverbally. Proceedings of the National Academy of Sciences of the United States of America, 105(27), 9163-8.

Meir, I., Aronoff, M., Börstell, C., Hwang, S.-O., Ilkbasaran, D., Kastner, I., Lepic, R., Lifshitz Ben-Basat, A., Padden, C., \& Sandler, W. (2017). The effect of being human and the basis of grammatical word order: Insights from novel communication systems and young sign languages. Cognition, 158, 189-207.

Schouwstra, M., \& Swart, H. de. (2014). The semantic origins of word order. Cognition, 131(3), 431-6. 